\title{
ALGUMAS REFLEXÕES SOBRE O DOCUMENTÁRIO ARQUEOLÓGICO
}

\author{
Sarah de Barros Viana Hissa ${ }^{1}$
}

\section{RESUMO}

O documentário, entendido como recurso midiático de grande potencial para difusão do conhecimento arqueológico, é geralmente proposto a partir da fórmula: nós falamos de nós para vocês (DA-RIN, 2006). Contudo, a Arqueologia já trabalha sob outra premissa: nós falamos de nós para nós. Esta fórmula faria sentido tanto no caso de documentários produzidos tendo como público alvo a própria comunidade arqueológica, quanto para a comunidade não científica. Para atender aos distintos públicos da melhor forma, os documentários arqueológicos podem tomar formas diferentes do modelo expositivo, com vários recursos de edição, roteiro ou imagem, problematizando conceitos de temporalidade, memória, autenticidade, verdade e entretenimento.

Palavras-chave: documentário arqueológico; entretenimento; difusão.

\section{ABSTRACT}

The documentary, as a media resource of great potential for extroversion of archaeological knowledge, is usually formulated as we speak about us to you. However, archaeology has been working, from public archaeology, under another premise: we speak about us to ourselves. This formula would make sense both in the case of documentaries produced for the archaeological community as for the non-scientific community. In order to best serve several publics, archaeological documentaries can take forms different from the expositive model, with several resources of editing, script or image, discussing concepts such as time, memory, authenticity, truth and entertainment.

Keywords: archaeological documentary; entertainment; extroversion.

\section{RESUMEN}

El documental, según un gran potencial de recursos multimedia para la difusión del conocimiento arqueológico, por lo general se propone partir de la fórmula: se habla de nosotros a usted. Sin embargo, la arqueología ha trabajado en otra premisa: se habla de nosotros para nosotros. Esta

\footnotetext{
${ }^{1}$ Doutoranda em Arqueologia no Museu Nacional da UFRJ (MN/UFRJ). sarah.hissa@gmail.com
}

\begin{tabular}{|l|l|l|l|l|l|l|}
\hline (C) Rev. Arqueologia Pública & Campinas, SP & v.9 & n.3 & $42-56$ & DEZ-2015 & ISSN 2237-8294
\end{tabular}


fórmula tendría sentido tanto en el caso de los documentales producidos teniendo como objetivo la comunidad arqueológica, y para la comunidad no científica. Para cumplir con los diferentes públicos de la mejor manera, los documentales arqueológicos pueden tomar diferentes formas del modelo de exposición, con las varias funciones de edición, la escritura o la imagen cuestionando conceptos de temporalidad, la memoria, la autenticidad, la verdad y el entretenimiento.

Palabras clave: documental arqueológico; entretenimiento; difusión.

\section{Introdução}

A Arqueologia interessa ao público em geral. Esta é a perspectiva de Cornelius Holtorf (2007). O arqueólogo discute o que o público não arqueólogo busca no passado, ressaltando o apelo que este exerce sobre as pessoas. Segundo o autor, elas travam uma relação de interesse, curiosidade e fascínio frente à Arqueologia. Essa forma de perceber o passado e a memória se relaciona tanto com a identidade coletiva, quanto com a identidade pessoal. Trata-se, portanto de uma questão também de pertencimento, de memória e de valorização cultural do passado. É ainda, por outro lado, uma questão de contemplação, de mistério, do desconhecido e do constante não saber.

Por outro lado, a comunicação é um aspecto que sempre fez parte das ciências, mesmo que somente através do diálogo entre pares. Nas palavras de Peter Fowler (2007), "communication is the lifeblood of archaeology"2. Desde antes das aparições de Mortimer Wheller na mídia dos anos 1950, a Arqueologia tem sido tema de programas de rádio e televisão e suscitado interesse popular. O passado que as pessoas selecionam e que denominam seus se trata de uma questão de identidade - questão tão própria da modernidade - por meio da construção de memórias coletivas.

Com isso em mente, voltando o olhar para a história da nossa disciplina, desde a década de 1980, a Arqueologia busca ser uma matéria, entre outras coisas, mais autocrítica e engajada, conscientemente voltada para questões sociais do presente e para as comunidades locais. Em outras palavras, coloca-se a seguinte questão: o que legitima a própria existência da Arqueologia é o conhecimento em si mesmo ou o conhecimento para a sociedade (ou, ainda, o conhecimento da sociedade ou o conhecimento com a sociedade)? Essa questão pode se traduzir ainda em outras: Qual a natureza da relação travada entre as comunidades e a ciência e, mais importante, como ela deve ser? O que as pessoas esperam da Arqueologia? O objeto da Arqueologia deve ser o que os não arqueólogos desejam como memória ou aquilo que o arqueólogo considera de relevo ou essencial? É possível integrar esses dois objetivos? Estas questões dizem respeito às bases da própria disciplina, uma vez que tratam da sua finalidade. Várias respostas a estas questões passam por Arqueologias a serviço do público leigo ou produzidas por comunidades locais. Além disso, essas questões são fundamentais para se pensar o gênero documentário sobre o passado e sua relevância

2 "Comunicação é a essência da arqueologia". Tradução minha. 
para as comunidades leigas. O documentário oferece um grande potencial de comunicação com o público em geral. Ele pode associar elementos lúdicos e pedagógicos, desse modo podendo atingir várias faixas etárias, grupos sociais ou níveis de escolaridade. Essa capacidade de alcance do documentário se multiplica, em termos numéricos, quando pensamos nos meios de difusão virtual.

Convidamos o leitor a imaginar um tipo ideal de documentário histórico ou arqueológico tradicional, marcado por uma narrativa unilateral comprovada por objetos materiais e diplomas. Esse documentário tradicional caminharia junto às noções de um passado linear, de continuidade homogênea, de verdade única, de personalidades suprassignificativas e de um ritmo temporal marcado por datas e eventos documentais. Com certeza, todos nós já assistimos documentários deste tipo.

Como alternativa, podemos conceber que o documentário sobre o passado - ou especificamente o documentário sobre Arqueologia - pode ser voltado para a divulgação de pesquisas e o engajamento de comunidades locais, para levantar questões e atrair a atenção do público para determinado tema, para convidar o espectador a se posicionar frente aos dados ou conclusões propostas, para expor noções sociais enraizadas e questionar práticas atuais, para abordar os espectadores de maneira pessoal ou tratar de temas universais como nossa própria existência, para exercícios estéticos ou sensitivos da comunicação e do entretenimento, para instigar novas interpretações e desafiar concepções tradicionais de aprendizado, ou mesmo para a educação pedagógica no sentido mais tradicional do termo. Assim, entre todas as possibilidades, pensamos que, os documentários sobre o passado, devido ao seu potencial de comunicação de massa e de instrumento de exercício intelectual, devem refletir uma nova noção de passado, como também de interação com o público.

\section{Conceituando o documentário}

Entendendo o documentário como construção, Sérgio Puccini (2009) descreve etapas deste processo (etapas que podem estar presentes em diferentes graus ou ordem). Puccini descreve uma série de etapas apenas para a pré-produção do documentário: roteiro e cenas dramáticas, proposta, pesquisa (que pode envolver pesquisa de arquivo, pré-entrevistas e trabalho de campo), argumento (envolvendo descrições da sinopse, dos personagens, da estrutura discursiva, do espaço e do tempo do documentário) e tratamento (escolhas acerca da imagem, som e formatação). Depois dessas etapas precedentes à filmagem (que, por sua vez, pode apresentar várias situações, tais como entrevistas, encenações, filmagem autônoma, plano e tomada), o autor elabora o processo até sua montagem e edição. Um elemento de relevo na pós-produção, para Puccini, é o corte, que permite a construção de uma seqüência de eventos essencialmente narrativa. Outro elemento

\begin{tabular}{|l|l|l|l|l|l|l|}
\hline (C) Rev. Arqueologia Pública & Campinas, SP & v.9 & n.3 & $42-56$ & DEZ-2015 & ISSN 2237-8294 \\
\hline
\end{tabular}


essencial da montagem refere-se à indissociabilidade entre o fazer e o pensar, que permeia toda produção intelectual.

Salles (2005), ainda que reconhecendo seu caráter construído, aponta para a dificuldade em se definir um filme documentário, dada a multiplicidade de estilos e formas possíveis: "o gênero documentário, ao contrário do cinema ficcional clássico, jamais contou com a força estabilizadora da indústria para impor convenções estilísticas e padrões narrativos relativamente homogêneos" (p. 58). Esse fato, apesar de parecer um complicador, pode ser visto também como libertador, já que teoricamente as convenções restringem menos que em outros gêneros.

Possíveis definições para documentário, segundo Salles, passam pela autodefinição do cineasta, a aceitação pelas instâncias de consagração (próximo do sentido bourdieusiano do termo) e a maneira pela qual o filme é assistido (distinguindo o gênero e o modo de compreensão do filme). De acordo com essa última definição de documentário, um filme de ficção também documenta algo, tal como estilos de atuação ou de fotografia. Nesse sentido, os vídeos domésticos, hoje gravados em meio digital, apresentam um desafio conceitual do documentário: eles podem ou não ser considerados documentários? Esses vídeos são muitas vezes editados em programas caseiros (onde, além das ações básicas de montagem - corte, efeitos simples de transição de planos e sequenciamento - se pode incluir títulos, créditos, intertítulos, trilha sonora, imagens estáticas, e voice over), o que dá margem à criatividade narrativa das pessoas, e a internet, especialmente via youtube e Google vídeos, possibilitam sua difusão. São documentários dissociados das redes consagradas, porém documentam pontos de vista.

Apesar dessas possibilidades de definição do documentário, para Salles, são outros dois elementos que o caracterizam, a saber: o contrato entre o filme e o espectador perante a realidade de certos de seus aspectos (tais como a existência histórica de personagens ou eventos) - ainda que a noção de existência e realidade desses seja problematizada - e a decorrente responsabilidade ética do cineasta com tais elementos já determinados como existentes. A responsabilidade ética frente aos elementos sobre os quais o documentário se baseia reside no fato de que esses elementos possuem uma vida externa ao documentário, de modo que toda fala sobre eles será apenas parcial e potencialmente enviesada. Para Nichols (2005), é o próprio conceito de representação de um evento ou indivíduo no documentário - conceito que é essencial para um filme desse gênero - e seus efeitos imprevisíveis frente o público que levanta o problema ético. Desse modo, a dimensão externa e futura do documentário se releva, frente a qual não se tem controle ou previsão. Não que o filme adquira uma vida própria e independente daquela previamente concebida pelo diretor, mas existe uma parcela de desdobramentos ou continuidade do documentário, que reside no próprio espectador, que pode independer - ainda que parcialmente - das intenções originais do filme. 
Essa solução para o problema da definição de documentário - o aspecto ético da atividade - resulta da compreensão do filme não-ficcional como uma construção criativa e autoral de estrutura e narrativa, não qual não se apenas descreve fatos. Desse modo, ainda, o elemento essencial do documentário é mais a forma de se contar uma história do que o tema da história em si e a criatividade deve ser contida em prol de uma realidade fixa, ainda que inatingível. Nichols (2005) aponta para a possibilidade de várias vozes possíveis - várias representações documentárias sobre um mesmo tópico. O autor argumenta tomando como base dois documentários Speak body (1987) e Abortion Stories: North and south (1984) que tomam posturas diferentes em relação ao aborto. Nesse caso, a ética não se dá frente uma realidade fixa, mas realidades subjetivas, relativas à opinião.

Da-Rin levanta outra questão de natureza social e ética, ao pensar o cinema autoreflexivo. Este, no limite, potencialmente se distancia em demasia da noção de realidade e de compromisso social do documentário. Em outras palavras, Da-Rin (1997) conclui que a tendência anti-ilusionista no documentário, apesar de frutífera no campo estético e formal, arrisca conclusões niilistas sobre o fato e a verdade, podendo "contribuir para a diluição de nossa consciência histórica" (DA-RIN, 1997: 85). Nichols (2005) levanta outra questão relativa ao problema ético da representação vídeo-documental e seu impacto nas imagens das pessoas. Trata-se da relação agente / vítima entre grupos. Grupos minoritários podem ser representados como grupos subalternos, vitimizados, dominantes ou autosuficientes e ativos. Salles conclui, por outro lado, que a função primordial do documentário não deve ser a transformação social, mas a proteção ética do personagem. A própria definição de documentário se torna a maneira pela qual é construído.

Finalmente, tanto Puccini (2009) quanto Salles (2005) e Nichols (2005) falam do documentário como uma interação entre um "eu" e um "outro". Essa relação de alteridade se baseia numa distância que se refere ao controle do filme, mas também se refere a uma proximidade com o tema abordado. Tanto Salles (2005) quanto Nichols (2005), pensando no documentário não tradicional, concluem uma fórmula ideal: nós falamos de nós para vocês.

Pensamos que essa fórmula ideal, no entanto, não seja suficiente para o caso da Arqueologia. Um formato distinto deste no que tange a interação entre os envolvidos pode ser oferecido: nós falamos de nós para nós. Esta fórmula faz sentido tanto no caso de documentários produzidos tendo como público alvo a própria comunidade arqueológica, quanto para a comunidade não científica. Não se apresenta aqui uma premissa inovadora na disciplina, mas reitera-se que, deste modo, o arqueólogo (ou o documentarista que tematiza o passado) não somente se reinsere na sociedade, mas também insere a sociedade no seu trabalho e no vídeo-documentário.

Os modos do documentário: entre a poesia, a informação e o outro

\begin{tabular}{|l|l|l|l|l|l|l|}
\hline (C) Rev. Arqueologia Pública & Campinas, SP & v.9 & n.3 & $42-56$ & DEZ-2015 & ISSN 2237-8294
\end{tabular}


Bill Nichols (2005) descreve seis modos de documentário, associando cada tipo a uma década quando era dotado de maior prestígio, a saber: poético (dec. 1920), expositivo (dec. 1920), observativo (dec. 1960), participativo (dec. 1960), reflexivo (dec. 1980) e performático (dec. 1980). Esses seis modos de documentário são classificados pelo autor não pelo seu tema ou conteúdo, mas pela sua forma. $O$ modo poético trabalha especialmente o lado estético do filme e é extremamente abstrato, enquanto o modo expositivo é didático e enfatiza uma maneira autoritária e onisciente de narrativa (voice over), conferindo uma impressão de objetividade. $O$ modo observativo evita comentários, letreiros, entrevistas e encenações, enfatizando as pessoas e suas atividades. A presença do diretor e sua equipe, assim como do roteiro, é minimizada. Trata-se do chamado cinema direto, que se diz apreendendo a realidade como ela é. O documentário direto parece colocar em cheque a importância do roteiro, já que se captura o que já está ou acontece independentemente do filme. No entanto, segundo Pucinni (2009), esse documentário apenas desloca o roteiro para a etapa de montagem e, ainda sim, depende da sensibilidade do diretor frente ao que está sendo filmado. Já o modo participativo incorpora entrevistas e imagens de arquivo, montando um argumento específico. Ele é invasivo e difere do modo expositivo por incorporar de maneira direta o diretor / entrevistador. Busca enfatizar as subjetividades da produção fílmica e a concepção do filme. O modo reflexivo é abstrato, buscando desafiar convenções formais do cinema, tais como enquadramento e a noção de realidade da representação. Trata-se de um movimento mundial antinaturalista, que ressalta o caráter artificial da produção cinematográfica, incluindo o documentário, se utilizando de estratégias anti-ilusionistas do cinema não ficcional (DA-RIN, 1997). Esse movimento implicou uma renovação formal dos filmes, dando margem a experimentações em edição, estrutura, roteiro, fotografia, sonografia, etc. Segundo Da-rin (2008), noções de autoreflexividade nas artes plásticas remontam ao autoretrato e a pinturas como O casal Arnolfini, 1434 (Jan van Eyck) e As meninas, 1656 (Velásquez). Já sobre esse modo de vídeo documentário, Da-Rin expressa que esses "acionam estratégias de distanciamento crítico do espectador e frequentemente lançam mão da ironia, da paródia e da sátira" (DA-RIN, 2006: 135). Filmes de tendência anti-ilusionista foram raros no Brasil até o início dos anos 1980, apesar de haver discussões a respeito (DA-RIN, 1997). Entre os documentaristas que experimentaram essa ótica fílmica, Da-Rin (1997) destaca Arthur Omar, Jorge Furtado e Eduardo Coutinho. Já no modo performático, os documentaristas usam-se excessivamente de estilo e da sensibilidade do espectador, por meio do acesso a subjetividades. Segundo Nichols (2005), esses modos podem aparecer em épocas distintas daquela apontada no modelo que oferece, assim como mais de um pode fazer parte de um único filme.

Pode-se perceber que a relação entre objetividade e subjetividade é uma recorrência nesses modos de documentário. O modo poético rejeita a objetividade e se concentra na subjetividade contemplativa. No limite, o documentário pode ser também uma experiência estética, mesmo se tematizar a Arqueologia ou o passado (ou mesmo física de partículas), mesmo sem

\begin{tabular}{|l|l|l|l|l|l|l|}
\hline (C) Rev. Arqueologia Pública & Campinas, SP & v.9 & n.3 & $42-56$ & DEZ-2015 & ISSN 2237-8294
\end{tabular}


perder precisão, caráter informativo ou educacional. O modo expositivo encontra sua objetividade na autoridade e onisciência do voice over, enquanto o modo observativo, na idia de apreender a realidade sem mediação (apesar da presença certeira dos cortes, seleções e montagem). O modo participativo abraça a opinião do filme e constrói seu argumento abertamente. Da mesma forma, o documentário reflexivo toma o próprio documentário como tema de discussão, sob a concepção de que não há realidade pura. Já o modo performático novamente se volta para as subjetividades.

Estes seis "modos" do documentário agrupam, em tipos, características que podem aparecer no gênero fílmico. Essas características, quando associadas, carregam mensagens sobre como se percebe o tema discutido em dado documentário, sobre o objetivo do filme, sobre a relação que se trava entre os envolvidos e o papel de cada um na construção do enredo. Estas mensagens, contudo, estão carregadas mais especificamente em características formais do vídeo. Interessou ressaltar, com este panorama sucinto, que mesmo documentários podem tomar formas distintas do modelo expositivo, sendo que vários recursos de edição, roteiro, imagem, etc., são utilizados para tal.

O seguinte segmento deste texto tratará especificamente de mensagens intrínsecas ao conteúdo do documentário arqueológico e questões que este pode levantar.

\section{Documentário arqueológico: o tradicional e o não tradicional, entre conceitos de temporalidade, memória, autenticidade, verdade e entretenimento}

João Salles (2005), Sílvio Da-Rin (2007a, 2007b) e Bill Nichols (2005) apresentam e discutem principalmente documentários de cunho antropológico ou sociológico, como greves, movimentos políticos, questões sociais, identidade nacional, debates polêmicos, biografias de celebridades. É evidente que todas essas questões têm caráter também histórico, mas os documentários que se utilizam diretamente de fontes documentais ou arqueológicas, tratando de períodos longos de tempo (ao invés de eventos específicos e pontuais), foram pouco mencionados.

No entanto, Nichols (2005) e Salles (2005) discutem, ainda que brevemente, a maneira ímpar que os documentários envolvem a temporalidade, questão chave para o estudo histórico ou arqueológico. Nessa perspectiva, mesmo quando focalizando o tempo presente, os documentários trabalham com os tempos presente e passado, onde os efeitos do passado são percebidos no presente. Ou seja, o passado é sempre latente no presente. Um dos efeitos do passado no presente é a memória e ela participa da ação presente: "a memória é parte das várias maneiras como os espectadores se servem do que já viram para interpretar o que estão vendo" (NICHOLS, 2005: 90).

Para Nichols, a memória é parte fundamental do documentário, qualquer que seja o tema abordado. Ela faz parte da construção do filme e da sua absorção pelo espectador, servindo como base para associação de novas ideias. Sobre a memória, Cornelius Holtorf (2007a), com base no 
trabalho de Pierre Nora, distingue duas memórias: através da história (que é uma construção, voltada para parar o tempo e manter o não esquecimento, e um fenômeno específico da nossa sociedade atual) e a memória real, que está sendo substituída pela memória interpretada. O documentário seria também uma memória interpretada, ao passo que é construída através de criatividade e de escolhas. Holtorf então se pergunta: "a importante questão sobre a memória é por que as pessoas se lembram do passado de determinada maneira, em determinado momento" (2007a). O arqueólogo está ressaltando os aspectos subjetivo e pessoal da memória, sobre os aspectos objetivo e coletivo. A memória não somente é uma construção arqueológica, mas também das pessoas em geral, e é possível compreender as razões da sua configuração.

A memória real, da qual fala Nora (HOLTORF, 2007a, op cit), remete à questão do real e verdadeiro versus o fictício ou falso, questão também cara ao documentário. Essa prevalência da verdade única é a base do contrato do qual fala Salles (2005), travado entre o espectador e o filme / cineasta. Os espectadores, portanto, buscam ser informados e educados, de maneira precisa e ilustrativa. Isso remete à própria relação que a sociedade trava com a ciência de modo geral. A Universidade e as instâncias de pesquisa, na voz de professores, pesquisadores e especialistas, detêm algo distinto do restante das pessoas: conhecimento. Esse conhecimento deve, portanto, ser algo de extraordinário e revelador, para justificar o próprio trabalho de pesquisa. A ciência, então, desempenha um papel pedagógico na sociedade, enquanto essa última observa passivamente e à distância.

O conceito de autenticidade, no que diz respeito aos objetos arqueológicos ou ao documentário, é relacionado às ideias de verdade e realidade, porém, com implicações específicas (HOLTORF, 2007a). Enquanto o real e o verdadeiro são diretamente desejados, a autenticidade promete distância, reverência e mística, portanto também tolhe liberdades, emudece e obscurece.

Além disso, o passado não somente participa das pesquisas e interpretações arqueológicas, mas também legitima gostos, opiniões, posições sociais, etc. A autenticidade então confere uma anterioridade percebida, que é, em si mesma, um valor positivo (HOLTORF, 2007).

Para Angela Piccini (2007), os canais de TV, no que se refere aos documentários, precisam sentir que estão comunicando verdades, de maneira autêntica, precisa e real. Em decorrência disso, uma polêmica foi criada, voltada para determinar se os documentários e a TV archaeology ${ }^{3}$ produz ou não produz verdades. No entanto, a autora vê essa questão como infrutífera. Ao invés desse questionamento ocupar os debates acerca do documentário, Piccini (2007) propõe questionamentos sobre a função do documentário e seu formato. A arqueóloga propõe que, mesmo sem abandonar os fatos arqueológicos, os vídeos devem se afastar da montagem de evidência e de apenas contar algo

\footnotetext{
${ }^{3}$ Arqueologia veiculada pela televisão, portanto, visando atingir, informar ou entreter o público leigo em geral.
} 
sobre o passado, promovendo a autosuficiência do espectador. O que Piccini aponta como direcionamento é a aceitação da condição de entretenimento e do aspecto representativo do documentário e do próprio produto televisivo como cultura material.

Tendo em vista a questão acerca da verdade ou autenticidade veiculada pelo documentário e o papel da memória na construção de uma percepção crítica do mundo, várias opiniões se formaram a respeito do que seria a função ideal do documentário, assim como sua forma. Os documentários tradicionais que tematizam o passado, sejam eles históricos ou arqueológicos, apresentam um único olhar, trazendo uma interpretação unilateral. O especialista diplomado, detentor das respostas sobre determinado período, sítio ou artefato arqueológico ou sobre certo evento histórico, invenções, transformação social ou catástrofes, apresenta sua interpretação, corroborada por dados estatísticos, datações, objetos concretos e documentos históricos. Entre os elementos cinematográficos desse tipo de documentário estão entrevistas; narração em voice over, que tem sido um elemento intensamente criticado por documentaristas contemporâneos devido ao seu tom autoritário e onisciente (PUCCINI, 2009: 106); intertítulos, que pode aparecer como opção à narração; trilha sonora contemplativa; encenações; cenas de arquivo e montagem de evidência.

Pensando estes pontos, com base nos tipos de documentários propostos por Nichols (2005), o modo expositivo é certamente o mais comum em documentários de Arqueologia, onde se narra a verdade e o autêntico, construindo uma noção de memória concreta e factual. $\mathrm{O}$ modo participativo também é recorrente, valendo-se de vários recursos para construir uma noção do passado. A temporalidade que busca apresentar é única (além de linear), conferindo a impressão de que o documentário se refere apenas ao passado. A memória é a sequência de fatos históricos tidos como verdadeiros. Seu objetivo primeiro é mais informar, do que entreter. Este tipo de documentário apresenta um viés mais tradicional.

Para alguns arqueólogos, como é o caso de Peter Fowler (2007), estes documentários tradicionais, ao lado dos museus e escolas, são a forma mais adequada para comunicação com o público leigo, preferíveis, portanto, a outras formas midiáticas, tais como os filmes de ficção, games, internet, entre outros. Essa preferência pelo documentário revela não somente a preferência pela mídia tradicional, mas também demonstra uma percepção tradicional do próprio documentário, tido então como unilateral, autoritário e linear, de função unicamente pedagógica (e uma versão tradicional de educação) voltado para a apreensão dos fatos pelo espectador e a apresentação de resultados pelo especialista. Fowler defende um documentário intimamente próximo dos fatos e do controle do arqueólogo, voltado para a veiculação de dados e estímulo do interesse sobre o passado. Neste sentido, o documentário tem o propósito de educar ou de entreter, propósitos que também não se cruzam. A mídia deve então servir como veículo à ciência sob a forma de um documentário acadêmico, sério e intelectual. Todo outro tipo de tele-Arqueologia, termo utilizado pelo autor, não é propriamente Arqueologia. 
Contudo, como o próprio Nichols (2005) aponta, um único documentário pode apresentar mais de um modo por ele descrito. Muitos documentários, mesmo estes tradicionais, ao se ressaltar o caráter abstrato, incompreensível ou simbólico de qualquer vestígio arqueológico, pode-se dizer, recorrem para o lado estético e poético da Arqueologia. Este ponto poderá ser positivo, especialmente se trata de um documentário voltado para o grande público, no que este apelo ressalta a dúvida na construção da memória no presente e a distância entre presente e passado. Não é o próprio caráter expositivo que engessa este tipo tradicional de documentário, mas as noções de memória e de ciência nas quais se fundamentam.

Por outro lado, há arqueólogos que buscam outra relação entre Arqueologia e sociedade, como é o caso de Timothy Taylor e de Cornilius Holtorf. Para Taylor (2007), o papel do documentário deve ser o de questionar preconceitos e julgamentos sociais. Neste sentido, o arqueólogo apresenta o caso da dificuldade da aceitação na própria academia do canibalismo como prática entre os Anasazi e a capacidade da mídia de banalizar o sensacional (já que o conhecimento é também o que é considerado admissível), para que temas como o canibalismo se tornem mais aceitáveis e plausíveis como interpretações de vestígios arqueológicos e ações humanas, a partir da aceitação do diferente. Independente do resultado dessa polêmica específica, Taylor (TAYLOR, 2007: 200) propõe o documentário como um veículo de comunicação ímpar para a Arqueologia. Para o autor, a imagem em movimento proporciona uma proximidade entre o espectador e as pessoas que oferecem as informações que textos não apresentam, de modo a intensificar o potencial crítico da apreensão pessoal do dado veiculado. Além disso, o processo de absorção das imagens as associa à memória já construída, no exemplo acima, a partir de textos. Taylor (2007) pensa, ainda, que o poder dos documentários não está na propagação do conhecimento, mas no estímulo a novas maneiras de pensar. Holtorf coloca essa ideia de maneira diferente. Enquanto Taylor propõe certa autonomia ao espectador, mantendo a ideia de verdade, Horltorf problematiza conceitos como o de autenticidade e seu impacto na cultura popular.

Voltando aos conceitos de Nichols (2005), o modo documental observativo pode ser usado como um recurso forte para apresentar metodologia de trabalho arqueológico e questionar noções de fato e de verdade na construção do conhecimento. Neste modo, as atividades podem ser simplesmente oferecidas nas próprias imagens do trabalho. Pode-se imaginar documentários de cunho mais tradicional, do tipo expositivo, oferecendo essas imagens, porém curtas e como parte de um discurso que busca corroborar verdades. O interessante no modo observativo, contudo, seria ressaltar a forma pela qual os vários trabalhos arqueológicos são construídos lentamente e que as ditas verdades dependem de inúmeros procedimentos, tal como da combinação de resultados de trabalhos realizados por pesquisadores distintos. Desconstruir ou desnudar a própria disciplina seria congruente com o modo reflexivo, apresentando o potencial de construir um conhecimento mais crítico. O modo performático, ao buscar atingir subjetividades e sensibilidades do espectador, tem potencial de tocar as pessoas de forma mais pessoal. Outros elementos levantados por Nichols

\begin{tabular}{|l|l|l|l|l|l|l|}
\hline (C) Rev. Arqueologia Pública & Campinas, SP & v.9 & n.3 & $42-56$ & DEZ-2015 & ISSN 2237-8294
\end{tabular}


poderão ser úteis neste exercício de imaginar formas de tornar o documentário mais reflexivo e mais crítico, ou de instigar o expectador a questionar conceitos basilares, para além das funções informativas e de entretenimento da tele-Arqueologia. Contudo, para discutir estas ideias usando-se de um exemplo específico, trataremos brevemente de um estudo de caso de TV-Archaeology.

\section{O time-team: estudo de caso de tele-Arqueologia voltada para o público leigo}

A produção inglesa Time Team - "A Equipe do Tempo", em livre tradução é um caso interessante para a discussão em tela. Trata-se de uma série de documentários arqueológicos produzidos pelo Channel 4, canal comercial britânico de TV (com spin off nos Estados Unidos, o Time Team America). O sucesso do programa desde 1994, que tem aproximadamente dois milhões de espectadores, resultou na sua persistência até 2013, apesar de que com alguma redução de orçamento. Em 2012, após quase 20 anos do primeiro episódio, Mick Aston reclama que o programa perdeu grande parte do caráter arqueológico, razão pela qual abandona o programa ${ }^{4}$. A última temporada do programa foi ao ar então em 2013. Nota-se que esteve no ar por 19 anos, um programa estritamente de Arqueologia.

O programa cobre sítios arqueológicos do Paleolítico até da Segunda Guerra Mundial, tendo 3 dias para escavar parcialmente um sítio e oferecer algum tipo de interpretação. A escolha do local a ser trabalhado envolve a busca por uma questão específica e proposta antes da escavação, relativa a um período específico, sendo que, muitas vezes quem convida o programa, oferecendo localidades e questões a serem trabalhadas, é a comunidade ou arqueólogos locais, fato ressaltado várias vezes pelo programa.

A abertura de várias quadras de escavação; a inclusão de vários especialistas (muitos deles vindos das ciências duras, como geofísica, em levantamentos topográficos, em Arqueologia Forense, em Arquitetura, sobre estruturas arqueológicas, em períodos específicos da história inglesa); a extensa utilização de recursos visuais elaborados (como reconstituições artísticas e encenações), auxiliando a visualização de tempos e arranjos passados da paisagem e inserindo sítios e estruturas nos mapas de época e em imagens de satélite atuais; a sobreposição dos vários períodos de ocupação inglesa (passando pelo período Paleolítico, Neolítico, Romano, Saxão, Normando, Medieval, Tudor, Vitoriano, Primeira e Segunda Grandes Guerras); a montagem de evidência, os planos curtos e as filmagens de câmera direta; dão a impressão de um trabalho dinâmico e complexo.

\footnotetext{
${ }^{4}$ http://www.westerndailypress.co.uk/Professor-Mick-Aston-quits-Time-Team-dumbing-row/story15177582-detail/story.html
}

\begin{tabular}{|l|l|l|l|l|l|l|} 
(C) Rev. Arqueologia Pública & Campinas, SP & v.9 & n.3 & $42-56$ & DEZ-2015 & ISSN 2237-8294
\end{tabular}


O quadro principal do Time Team é composta pelo apresentador Tony Robinson (excomediante) e, dois arqueólogos: Mick Aston e Phil Harding. Mick Aston graduou-se na Birmingham University e não terminou o doutorado. Trabalhou para o Oxfordshire County Museum, foi arqueólogo do governo para o condado de Somerset e, em seguida, se tornou professor pela Universidade de Bristol. Holtorf (2007) oferece algumas falas de Aston sobre os arqueólogos e sua maneira de se apresentar e vestir: "we're complete scruffbags (...), but I don't care. I'm not remotely interested in appearances, life's too short for that" ${ }^{5}$. No entanto, seus agasalhos coloridos são motivo de riso e menção, ao mesmo tempo em que possui uma imagem intelectual e confiável. Por outro lado, Phil Harding não possui formação acadêmica, tendo se treinado como arqueólogo de campo em escavações da Universidade de Bristol, da Southampton Unit, do Museu Britânico e da Wessex Archaeology, onde ainda trabalha. A Wessex Archaeology produz vários dos relatórios de campo das escavações do Time Team. Para Moser (HOLTORF, 2007: 84), Harding, com o cabelo comprido, jaqueta e chapéu, simboliza o tipo do cowboy e os elementos do aventureiro e explorador presentes na imagem popular de arqueólogo. Harding é, ainda, um personagem cômico e descontraído, sempre se surpreendendo e se entusiasmando intensamente com os artefatos encontrados e com as interpretações construídas.

Esses dois arqueólogos, combinados com o apresentador vindo do gênero da comédia, conferem ao programa e à Arqueologia um tom de descontração e relacionam a Arqueologia à diversão. Por outro lado, o trio principal masculino, relega as pesquisadoras ou arqueólogas de campo a uma posição secundária no programa, apenas auxiliando as escavações ou corroborando interpretações. Por outro lado, para Holtorf (2007), a popularidade do Time Team se nutre da proximidade travada entre o apresentador Tony Robinson e o público e da relação popularmente travada entre Arqueologia e mistério, descoberta, solução de pistas. De fato, o programa enfatiza especialmente o artefato, que é utilizado mais para datação do que para exibição em si ou contextualização de um período, e também no próprio solo. O programa parece apresentar estes elementos como os lócus principais da informação necessária para compreender o passado obscurecido pelo tempo.

Entre as críticas recebidas pelo Time Team por parte da comunidade arqueológica estão: a ênfase na escavação, dando margem à noção de que essa é a única atividade informativa da Arqueologia (FOWLER, 2007); o uso de uma fórmula já estabelecida e repetitiva dos episódios, formando algo como uma novela (TAYLOR, 2007) e a ausência de questionamentos sobre a nossa própria humanidade (TAYLOR, 2007). A essas se pode ainda adicionar a ênfase na história inglesa, que produz uma percepção encaixotada e isolacionista do passado, e a distância que a noção de um trabalho complexo pode produzir frente ao público em geral. Entre os benefícios do programa para a

5 "Nós somos completos molambos (...), mas eu não me importo. Não estou nem remotamente interessado em aparências, a vida é muito curta para isso". Tradução minha.

\begin{tabular}{|l|l|l|l|l|l|l|} 
(C) Rev. Arqueologia Pública & Campinas, SP & v.9 & n.3 & $42-56$ & DEZ-2015 & ISSN 2237-8294
\end{tabular}


crítica especializada (peer review) estão a popularização da Arqueologia e do estudo do passado entre o público em geral (TAYLOR, 2007), que pode inclusive trazer facilidades de natureza política à disciplina, e a demonstração das técnicas e dos desafios intelectuais da Arqueologia (FOWLER, 2007).

Esta tele-Arqueologia, se incluída na dicotomia criada até então - entre documentário tradicional e documentário não tradicional - não se enquadraria inteiramente em nenhuma das duas.

O programa apresenta características tradicionais, como a ênfase no objeto, a montagem de evidência, as interpretações diplomadas, o tempo compartimentado dos períodos arqueológicos e a linearidade do episódio, ao mesmo tempo em que também oferece uma leveza e proximidade com os personagens centrais, aproximando o espectador do filme, oferece a evidência suplementar de Taylor (2007), e traz uma narrativa pessoal e questionável, por meio da figura do apresentador Tony Robinson.

Ao mesmo tempo, tanto Robinson quanto Harding são performáticos, no sentido de que incorporam a surpresa e êxtase que se espera do público, na identificação de achados interessantes, de forma que se identifica com os 'personagens'. Aston e Harding incorporam também imagens distintas e complementares do que se espera de um arqueólogo: o cientista e o aventureiro. Os recursos visuais permitem uma imersão em uma possibilidade do passado, que cativa o expectador.

Por fim, o Time Team alcançou como conquista a difusão da mágica que a Arqueologia oferece no meio popular, da qual fala Horltorf (2007), ainda que fortemente restrita ao Reino Unido. Apresenta a Arqueologia como entretenimento e permite o espectador acompanhar o processo investigativo de forma digerível. Ainda, ao incorporar pesquisadores de várias áreas, explicita que a Arqueologia não é única detentora do conhecimento que necessitamos para entender a evidência arqueológica ou o passado.

\section{Considerações finais}

Em primeiro lugar, defende-se aqui a necessidade (ou a utilidade) de se valer de documentários arqueológicos, tanto para divulgação das pesquisas em meio especializado, quanto na comunicação com o público leigo em geral. No limite, a Arqueologia se beneficia de qualquer tipo de documentário arqueológico, para fomentar a função social da disciplina tanto como aprendizado, quanto entretenimento. Contudo, tendo em vista as propostas mais recentes para a relação entre a Arqueologia e as comunidades locais, visando uma presença ativa do não arqueólogo nas pesquisas, assim como os movimentos mais recentes na teoria do cinema e do documentário, que

\begin{tabular}{|l|l|l|l|l|l|l|} 
(C) Rev. Arqueologia Pública & Campinas, SP & v.9 & n.3 & $42-56$ & DEZ-2015 & ISSN 2237-8294
\end{tabular}


pregam por uma experimentação estética, associadas à relação ética do filme com o objeto retratado e a presença também ativa do espectador, o documentário tradicional sobre o passado, unilateral, linear e autoritário, deixa de ser a única via possível.

Voltando à premissa do nós falamos de nós para nós, ressalta-se a proximidade potencial entre o arqueólogo (ou a autoridade no assunto documentado) e o espectador, colocando-se também como espectador. É importante também ressaltar que a própria comunidade arqueológica pode tomar o documentário como meio de veiculação científica entre os pares.

Esse falar envolve memória individual e coletiva, problematizar noções de autenticidade, de verdade e de realidade e, especialmente, buscar uma alternativa ao documentário tradicional, autoritário e linear. Entre as possibilidades estão a desconstrução da noção da Arqueologia como produtora de verdades e a reaproximação entre conhecimento e estética.

\section{Agradecimentos}

Este texto foi redigido no âmbito da disciplina "Arqueologia e Cinema", ministrada pelo prof. Andrés Zarankin no Programa de Pós-Graduação em Antropologia, com linha de pesquisa em Arqueologia (PPGAN / UFMG), a quem agradeço pelos comentários.

\section{Referências bibliográficas}

DA-RIN, Sílvio. Auto-reflexividade no documentário. IN: Cinemais: Revista de cinema e outras questões audiovisuais. Número 8, 1997. Pp. 71-92.

DA-RIN, Sílvio. Espelho partido: tradição e transformação do documentário. Rio de Janeiro: Azougue, 2006.

FOWLER, Peter. Not Archaeology and the media. IN: Archaeology and the media. California: Left Coast Press, 2007. Pp. 89-108.

HOLTORF, Cornilius. From Stonehenge to Las Vegas: Archaeology as popular culture. Oxford: Altamira Press, 2007a. 
HOLTORF, Cornilius. An Archaeological fashion show. IN: Archaeology and the media. California: Left Coast Press, 2007b.

MOSER, Stephanie (conversa pessoal com Holtorf) IN: HOLTORF, Cornilius. An Archaeological fashion show. IN: Archaeology and the media. California: Left Coast Press, 2007.

NICHOLS, Bill. Introdução ao documentário. Campinas: Papirus, 2005.

PICCINI, Angela. Facking it: Why the truth is so important for TV Archaeology. IN: Archaeology and the media. California: Left Coast Press, 2007. Pp.221-236.

PUCCINI, Sérgio. Roteiro de documentário: da pré-produção à pós-produção. Campinas: Papirus, 2009.

SALLES, João Moreira. A dificuldade do documentário. IN: MARTINS, José de Souza, ECKERT, C. e NOVAES, S. C. (orgs.). O imaginário e o poético nas ciências sociais. Bauru: EDUSC, 2005. PP. 57-71.

SCHABLITSKY, J. The way of the Archaeologist. IN: Box Office Archaeology. Julie Schablitsky (ed). California: Left COSAT Press, 2007.

SOARES, Mariza de Carvalho e FERREIRA, Jorge. A história vai ao cinema. Rio de Janeiro: Record, 2001.

TAYLOR, T. Screening Biases: Archaeology, Television and the Banal. Archaeology and the media. California: Left Coast Press, 2007. Pp.187-201. 